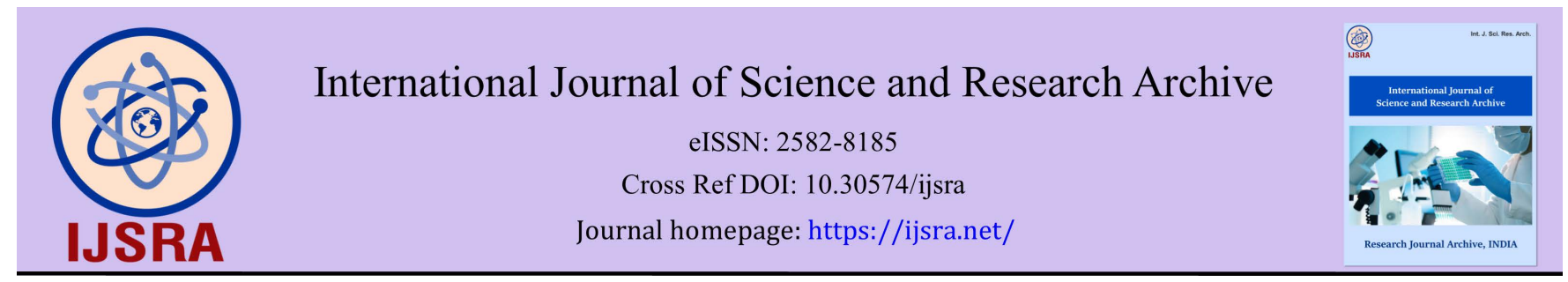

(RESEARCH ARTICLE)

Check for updates

\title{
The effect of $\mathrm{SiO}_{2}$ nanoparticles in polyurethane paint formulation on metal surfaces
}

\author{
Le Huy Hai * \\ Faculty of Chemical Engineering and Food Technology, Nguyen Tat Thanh University, Vietnam.
}

International Journal of Science and Research Archive, 2021, 03(01), 031-036

Publication history: Received on 11 June 2021; revised on 13 July 2021; accepted on 15 July 2021

Article DOI: https://doi.org/10.30574/ijsra.2021.3.1.0101

\begin{abstract}
Polyurethane (PU) paint is being widely used in industry and life. Currently, nanotechnology can create a variety of materials as small as nanometers with many applications, it has brought many outstanding properties to PU paint. The aim of this study is to investigate the effect of $\mathrm{SiO}_{2}$ nanoparticles in PU paint formulation on metal surfaces. We created a sample of two-component PU paint, part A is Desmophen A-160, Bentone 34, BYK 066, Disper 710S, Foamex N, Airex 900, $\mathrm{TiO}_{2}, \mathrm{SiO}_{2}$ nanoparticles, $\mathrm{BaSO}_{4}$, Cloparafin, Xylen, Thinner 132, Desmodur N75, and part $\mathrm{B}$ is a curing agent Desmodur N75. Methods of analyzing the properties of the PU paint film are based on Vietnam standards. The study results showed that $\mathrm{SiO}_{2}$ nanoparticles have increased the properties of the PU paint film, improving the Impact and Glossy of the PU paint film. $\mathrm{SiO}_{2}$ nanoparticles increase from $1 \%$ to $6 \%$ by weight, the Impact increased by about $21.62 \%$ (74 to $90 \mathrm{~kg} . \mathrm{cm}$ ), Glossy $60^{\circ}$ increased by about $13.75 \%$ (80 to 91). $\mathrm{SiO}_{2}$ nanoparticles are a good coating substance in PU paint, it improves the properties of the paint film, it increases the Impact and Glossy for the paint film. The higher the rate of $\mathrm{SiO}_{2}$ nanoparticles, the better the properties of the PU paint film. Because the cost of nanomaterials is higher than that of normal coating materials, the nanomaterial should only be added with a ratio of about $2-4 \%$ by weight.
\end{abstract}

Keywords: Coating powder; Metal surface; Nanotechnology; Polyurethane paint; $\mathrm{SiO}_{2}$ nanoparticles

\section{Introduction}

Polymers have become indispensable materials in recent years in the age of technology and science, it has a very important place in our daily lives. Polyurethanes (PU) are among the most useful polymers and are widely used both in industry and in consumer products $[1,2,3]$. Because of their special chemical structure, these materials have different properties such as varied hardness, excellent wear resistance, and good resistance to solvents, flexibility, and high strength. High compressive and tensile strength. Currently, PU has a very special position in the field of coatings $[4,5$, 6].

PU paint is a 2 component paint, part A is a mixture of polyurethane resin, additives and solvents; part B is a curing agent. Today, before the strong development of nanotechnology, the coating field has made great progress. Nanotechnology is considered as one of the keys to open the technology of the future. Nanomaterials have been widely used to improve the properties of PU due to their small size. Nanotechnology has researched and applied particles smaller than 100 nanometers $(\mathrm{nm})$ in at least one dimension, artificially produced nano-sized particles with new properties that are important for development of products in the field of coatings $[7,8,9]$.

Currently, the coating industry is developing very strongly in both quantity and type of paint used in industry, aviation, ships and life. Nanomaterials are increasingly widely applied in the field of coatings such as epoxy paint, alkyd paint, acrylic paint, PU paint, it has made the paint film more durable to the impact of the environment, better than paint without nanomaterials $[10,11,12]$. There have been many research works on nanoparticle addition in PU coating, the

\footnotetext{
${ }^{*}$ Corresponding author: Le Huy Hai

Visiting Lecturer of Faculty of Chemical Engineering and Food Technology, Nguyen Tat Thanh University, Vietnam. 
incorporation of metal oxide nanoparticles such as nanoalumina, nanosilica, nano zinc oxide, nano titanium dioxide, clay, cellulose nanocrystals, etc. coatings to improve the properties of PU coating films $[13,14,15,16]$.

In a study by Yern Chee Ching and Nurehan Syamimie investigated PU coatings with nano- $\mathrm{SiO}_{2}$ of about $16 \mathrm{~nm}$ in diameter. Friction and abrasion test is carried out using a piston wear tester, the wear surface of the coating film after the test is examined by optical microscope. The $\mathrm{PU} /$ nanosilica composite coating containing $3 \%$ by weight of nano-SiO 2 content provides the lowest coefficient of friction and wear rate to the substrate [17].

Our research group continues to investigate the addition of $\mathrm{SiO}_{2}$ nanoparticles in $\mathrm{PU}$ paint to metal surfaces. The purpose of the study is to investigate the Impact and Glossy of nano $\mathrm{SiO}_{2}$ on metal surfaces.

\section{Material and methods}

\subsection{Materials}

\section{- Desmophen A 160}

Desmophen A 160 is a polyacrylate resin bearing a hydroxyl group. It is used as a co-reactant in the formulation of two-component polyurethane coatings, Desmophen A 160 is also used in anti-corrosion coatings and coatings for steel.

\section{- $\quad$ Bentone 34}

Bentone 34 is a special clay mineral, it is a sodium-aluminum hydrosilicate. Bentone 34 is used to refer to natural stone, it is a very fine particle material that mainly consists of clay minerals.

\section{- $\quad$ BYK 066}

BYK 066 is defoamer for coatings, and ambient curing resin systems on the basis of PU resin.

\section{- $\quad$ Disper 710S}

Disper is an effective dispersant that disperses organic and inorganic additives in the paint to create a Gloss for paint film.

\section{- Foamex N}

Foamex $\mathrm{N}$ is effective against micro-foam in the stirring process.

\section{- $\quad$ Airex 900}

Airex 900 is a foam breaking agent, it breaks down bubbles formed in the process of grinding, mixing, to make the paint film glossy and smooth.

\section{- $\mathrm{TiO}_{2}$}

$\mathrm{TiO}_{2}$ is a compound with a high melting point (heat resistance), little chemical effect, abrasion resistance, large hardness but still remains stable, good plasticity, less cracking, $\mathrm{TiO}_{2}$ has a high coverage, fine particles, good oil permeability and very durable under the effect of moist air, seawater. $\mathrm{TiO}_{2}$ is not denatured over time, it is widely used in the paint industry.

\section{- $\mathrm{SiO}_{2}$ nanoparticles}

The silica nanopowder has an average particle size of 20-60 nm. $\mathrm{SiO}_{2}$ nanoparticles have small size, uniform distribution, high porosity, large specific surface area. It is used in paint production, which can greatly improve the toughness, wear resistance and aging resistance properties of the paint film. 


\section{- $\mathrm{BaSO}_{4}$}

Barium sulfate is an inorganic compound with the chemical formula BaSO 4 , Density: $4.49 \mathrm{~g} / \mathrm{cm} 3$. It is an odorless white crystalline substance and is insoluble in water. Barium sulfate is used as a pigment as a coloring additive for the paint industry, which can increase adhesion, keep the color bright, and not fade.

\section{- Cloparaffin}

Chlorinated Paraffin Oil is a clear or pale yellow liquid. Chlorine content: 51.7, Density (g/ml) at 25oC:1.26.

\section{- Xylene}

Xylene is a clear colorless liquid with a pleasant aroma. Auto-ignition temperature $500^{\circ} \mathrm{C}$. Density at $20^{\circ} \mathrm{C}$ is $0.865-$ $0.875 \mathrm{~kg} / \mathrm{l}$. This mixture is liquid, colorless.

\section{- Thinner 132}

Thinner 132 is a specialized mixed solvent product for dilution of two-component paints. It is combined from solvents with high solubility, medium volatility, it helps to add other outstanding properties such as waterproofing, anti-adhesion, anti-moss. It is a clear liquid, with a slight pungent odor of solvent, density $0.86 \mathrm{~g} / \mathrm{ml}$

\section{- Desmodur N75}

Desmodur N75 is soluble in esters, ketones and aromatic hydrocarbons such as ethyl acetate, butyl acetate, cyclohexanone, toluene, xylene. It is well compatible with the aforementioned solvents. Desmodur N75 is Desmophen A 160 resin curing agent.

\subsection{Method of Blending PU Paint Samples}

Table 1 Composition of PU paint formulations

\begin{tabular}{|c|c|c|c|c|c|c|c|c|c|c|}
\hline No & Component & $\begin{array}{l}\text { Raw } \\
\text { materials }\end{array}$ & Uses & $\begin{array}{l}\text { C } 1 \\
\text { Wt. } \\
\%\end{array}$ & $\begin{array}{l}\text { C } 2 \\
\text { Wt. } \\
\%\end{array}$ & $\begin{array}{l}\text { C } 3 \\
\text { Wt. } \\
\%\end{array}$ & $\begin{array}{l}\text { C } 4 \\
\text { Wt. } \\
\%\end{array}$ & $\begin{array}{l}\text { C } 5 \\
\text { Wt. } \\
\%\end{array}$ & $\begin{array}{l}\text { C } 6 \\
\text { Wt. } \\
\%\end{array}$ & $\begin{array}{l}\text { C } 7 \\
\text { Wt. } \\
\% \\
\end{array}$ \\
\hline 1 & \multirow{12}{*}{$\begin{array}{c}\text { Component } \\
\text { A }\end{array}$} & $\begin{array}{l}\text { Desmophen A- } \\
160\end{array}$ & $\begin{array}{l}\text { Resin } \\
\text { adhesion for } \\
\text { paint }\end{array}$ & 50 & 50 & 50 & 50 & 50 & 50 & 50 \\
\hline 2 & & Bentone 34 & $\begin{array}{l}\text { Anti- } \\
\text { sedimentation }\end{array}$ & 0.3 & 0.3 & 0.3 & 0.3 & 0.3 & 0.3 & 0.3 \\
\hline 3 & & BYK 066 & $\begin{array}{l}\text { Defoaming } \\
\text { Additives }\end{array}$ & 0.3 & 0.3 & 0.3 & 0.3 & 0.3 & 0.3 & 0.3 \\
\hline 4 & & Disper $710 \mathrm{~S}$ & $\begin{array}{l}\text { Dispersant } \\
\text { substance }\end{array}$ & 0.4 & 0.4 & 0.4 & 0.4 & 0.4 & 0.4 & 0.4 \\
\hline 5 & & Foamex N & Anti-foam & 0.2 & 0.2 & 0.2 & 0.2 & 0.2 & 0.2 & 0.2 \\
\hline 6 & & Airex 900 & $\begin{array}{l}\text { Foam breaking } \\
\text { agent }\end{array}$ & 0.3 & 0.3 & 0.3 & 0.3 & 0.3 & 0.3 & 0.3 \\
\hline 7 & & $\mathrm{TiO}_{2}$ & $\begin{array}{l}\text { Cover } \\
\text { substance }\end{array}$ & 18 & 17 & 16 & 15 & 14 & 13 & 12 \\
\hline 8 & & $\begin{array}{l}\mathrm{SiO}_{2} \\
\text { nanoparticles }\end{array}$ & $\begin{array}{l}\text { Cover } \\
\text { substance }\end{array}$ & 0 & 1 & 2 & 3 & 4 & 5 & 6 \\
\hline 9 & & $\mathrm{BaSO}_{4}$ & $\begin{array}{l}\text { Cover } \\
\text { substance }\end{array}$ & 2.5 & 2.5 & 2.5 & 2.5 & 2.5 & 2.5 & 2.5 \\
\hline 10 & & Cloparafin & $\begin{array}{l}\text { Plasticizer } \\
\text { Additives, } \\
\text { Chemical } \\
\text { resistance }\end{array}$ & 2 & 2 & 2 & 2 & 2 & 2 & 2 \\
\hline 11 & & Xylen & Solvent & 11 & 11 & 11 & 11 & 11 & 11 & 11 \\
\hline 12 & & Thinner 132 & Solvent & 15 & 15 & 15 & 15 & 15 & 15 & 15 \\
\hline
\end{tabular}


International Journal of Science and Research Archive, 2021, 03(01), 031-036

\begin{tabular}{|c|c|l|l|c|c|c|c|c|c|c|}
\hline 13 & $\begin{array}{c}\text { Component } \\
\text { B }\end{array}$ & $\begin{array}{l}\text { Desmodur } \\
\text { N75 }\end{array}$ & $\begin{array}{l}\text { Solidifying } \\
\text { agent }\end{array}$ & 18 & 18 & 18 & 18 & 18 & 18 & 18 \\
\hline & & Total & & 100 & 100 & 100 & 100 & 100 & 100 & 100 \\
\hline
\end{tabular}

We have blended PU coating formulations $\mathrm{C} 1, \mathrm{C} 2, \mathrm{C} 3, \mathrm{C} 4, \mathrm{C} 5, \mathrm{C} 6, \mathrm{C} 7$ with the same composition and different on $\mathrm{TiO}_{2}$ and $\mathrm{SiO}_{2}$ nano coating materials. The composition of $\mathrm{SiO}_{2}$ nanoparticles in the above formulas increased from $1-6 \%$ by weight (Table 1).

\subsection{Method of Creating PU Paint Film}

To evaluate the effect of $\mathrm{SiO}_{2}$ nanoparticles in $\mathrm{PU}$ paint formulation on metal surfaces we applied paint samples to metal surfaces. Each sample PU paint formulation was painted on 12 metal sheets measuring 70x150 mm and $0.5 \mathrm{~mm}$ thick with the same film thickness. We created a variety of patterns to then choose from. The paint film is created based on the Doctor Blade technique. A common tool for creating coatings in the lab is the manual film forming machine. We used manual scissors model BGD 201/5 with size $100 \mu \mathrm{m}$ from manufacturer Biuged. It is made of stainless steel with $2 \%$ accuracy, easy to use, produces a relatively uniform paint film.

\subsection{Methods of Analysis}

The drying time of the paint film is determined according to Vietnam Standard TCVN [22]. The coverage of dry paint film is determined according to Vietnam Standard TCVN [23]. The Gloss $60^{\circ}$ is determined according to Vietnam Standard TCVN [24]. The Impact is determined according to Vietnam Standard TCVN [25].

\section{Results and discussion}

Table 2 Properties of PU paint

\begin{tabular}{|c|l|l|c|c|c|c|c|c|c|}
\hline No & Properties & Unit & C 1 & C 2 & C 3 & C 4 & C 5 & C6 & C 7 \\
\hline 1 & Face dry time & minutes & 40 & 40 & 40 & 40 & 40 & 40 & 40 \\
\hline 2 & Natural drying time & hours & 12 & 12 & 12 & 12 & 12 & 12 & 12 \\
\hline 3 & Density $30^{\circ} \mathrm{C}$ & & 1.19 & 1.19 & 1.19 & 1.19 & 1.19 & 1.19 & 1.19 \\
\hline 4 & Smoothly & $\mu \mathrm{m}$ & 25 & 25 & 25 & 25 & 25 & 25 & 25 \\
\hline 5 & Impact level & $\mathrm{kg} . \mathrm{cm}$ & 74 & 76 & 80 & 84 & 87 & 89 & 90 \\
\hline 6 & Coverage of dry paint film & $\mathrm{g} / \mathrm{m}^{2}$ & 111 & 111 & 111 & 111 & 111 & 111 & 111 \\
\hline 7 & Glossy $60^{\circ}$ & & 80 & 81 & 84 & 87 & 89 & 90 & 91 \\
\hline
\end{tabular}

The data in Table 2 show that with increasing concentration of $\mathrm{SiO}_{2}$ nanoparticles, the degree of Impact also increases. Impact of PU paint formulations 1 to 7 rapidly increased from $74-90 \mathrm{~kg}$. $\mathrm{cm}$ when increasing the proportion of $\mathrm{SiO}_{2}$ nanoparticles from 1 to $6 \%$ by weight. Without adding $\mathrm{SiO}_{2}$ nanoparticles, Impact of $\mathrm{C} 1$ was $74 \mathrm{~kg} . \mathrm{cm}$, adding $1 \%$ of $\mathrm{SiO}_{2}$ nanoparticles, Impact of $\mathrm{C} 2$ increased by $2.70 \%$, adding $2 \%$ of $\mathrm{SiO}_{2}$ nanoparticles, Impact of $\mathrm{C} 3$ increased by $8.11 \%$, adding $3 \%$ of $\mathrm{SiO}_{2}$ nanoparticles, Impact of $\mathrm{C} 4$ increased by $13.51 \%$, adding $4 \%$ of $\mathrm{SiO}_{2}$ nanoparticles, Impact of $\mathrm{C} 5$ increased by $17.56 \%$, adding $5 \%$ of $\mathrm{SiO}_{2}$ nanoparticles. Impact of $\mathrm{C} 6$ increased by $20.27 \%$, adding $6 \%$ of $\mathrm{SiO}_{2}$ nanoparticles, Impact of $\mathrm{SiO}_{2}$ nanoparticles $\mathrm{C} 7$ increased by $21.62 \%$. Thus, the Impact index increased rapidly when $\mathrm{SiO}_{2}$ nanoparticles were added from 2 to $4 \%$ by weight.

The data in Table 2 show that as the concentration of $\mathrm{SiO}_{2}$ nanoparticles increases, Glossy also increases. Glossy $60^{\circ}$ of PU paint formulations 1 to formula 7 increased from 80 to 91. Without adding $\mathrm{SiO}_{2}$ nanoparticles, Glossy $60^{0}$ of $\mathrm{C} 1$ was 80 , adding $1 \%$ of $\mathrm{SiO}_{2}$ nanoparticles, Glossy $60^{\circ}$ of $\mathrm{C} 2$ increased by $1.25 \%$, adding $2 \%$ of $\mathrm{SiO}_{2}$ nanoparticles, Glossy $60^{\circ}$ of $\mathrm{C} 3$ increased by $5.00 \%$, adding $3 \%$ of $\mathrm{SiO}_{2}$ nanoparticles, Glossy $60^{\circ}$ of $\mathrm{C} 4$ increased by $8.75 \%$, adding $4 \%$ of $\mathrm{TiO}_{2}$ nanoparticles, Glossy $60^{\circ}$ of $\mathrm{C} 5$ increased by $11.25 \%$, adding $5 \%$ of $\mathrm{SiO}_{2}$ nanoparticles, Glossy $60^{\circ}$ of $\mathrm{C} 6$ increased by $12.50 \%$, adding $6 \%$ of $\mathrm{SiO}_{2}$ nanoparticles, Glossy $60^{\circ}$ of $\mathrm{C} 7$ increased by $13.75 \%$. Thus, the Glossy $60^{\circ}$ index increased rapidly when $\mathrm{SiO}_{2}$ nanoparticles were added from 2 to $4 \%$ by weight. 
The data in Table 2 show that when increasing the concentration of $\mathrm{SiO}_{2}$ nanoparticles, the Impact level and $\mathrm{Glossy}^{60} 0^{0}$ of the PU coating film also increase. This can explain that $\mathrm{SiO}_{2}$ nanoparticles are very small and fine, so they create Glossy on the metal surface. This issue has also been raised in some previous studies on nano coatings in paints. $\mathrm{SiO}_{2}$ nanoparticles are oxide nanostructured particles with spherical or multifaceted high surface areas. $\mathrm{SiO}_{2}$ nanoparticles are $\mathrm{SiO}_{2}$ particles with a molecular size smaller than $100 \mathrm{~nm} . \mathrm{SiO}_{2}$ nanoparticles have the advantages of low density, thermal stability, mechanical stability, and inertness. Particle size plays a very important role in the application of silica nanomaterials to $\mathrm{PU}$ coatings. $\mathrm{SiO}_{2}$ nanoparticles have porosity so the surface area is large, $\mathrm{So} \mathrm{SiO}_{2}$ nanoparticles are easy to adsorb. $\mathrm{SiO}_{2}$ nanoparticles are insoluble in water and any solvents, non-toxic, odorless. $\mathrm{SiO}_{2}$ nanoparticles are very chemically inert, it does not react with Oxygen, Chlorine, Bromine, and acids even when heated.

Incorporation of nanoparticles into PU paint is a solution to enhance coating durability as fine particles dispersed in the coating can fill the voids, reducing the porosity of the paint film. Nanoparticles can also prevent PU separation during curing, making the coating more uniform. Nanoparticles tend to reduce pore defects as a result of local shrinkage during PU curing. In addition, PU coatings containing nanoparticles will protect against corrosion and reduce the tendency of the coating to blister or delamination

\section{Conclusion}

$\mathrm{SiO}_{2}$ nanoparticles are a good coating substance in PU paint, it improves the properties of the paint film, and it increases the Impact and Glossy for the paint film. We found that only $2-4 \%$ by weight of $\mathrm{SiO}_{2}$ nanoparticles should be added to $\mathrm{PU}$ paint because the cost of $\mathrm{SiO}_{2}$ nanoparticles is higher than that of conventional coating materials.

\section{Compliance with ethical standards}

\section{Acknowledgments}

The authors would like to thank Mr. Nguyen Huy Tong, former President of Vietnam Paint and Ink Association.

\section{References}

[1] Ayesha K. Polyurethane nanocomposite coatings: state of the art and perspectives. Polymer international. 2018; 67(11): 1470-1477.

[2] Praw M. Polyurethane coatings: A brief overview. Journal of Protective Coatings and Linings. 2013; 30(8): 34-39.

[3] Chen L, Chen S. Latex interpenetrating networks based on polyurethane, polyacrylate and epoxy resin. Progress in Organic Coatings. 2004; 49: 252-258.

[4] Eid AI, Motawie AM, Sadek EM. Synthesis and characterization of polyurethane coatings based on soybean oilpolyester polyols. Egyptian Journal of Petroleum. 2011; 20(2): 1-8.

[5] Xinrong S, Nanfang W, Kunyang S, Sha D, Zhen C. Synthesis and characterization of waterborne polyurethane containing UV absorption group for finishing of cotton fabrics. Journal of Industrial and Engineering Chemistry. 2014: 20: 3228-3233.

[6] Chattopadhyay DK, Dean CW. Thermal stability and flame retardancy of polyurethanes, Progress in Polymer Science. 2009; 34: 1068-1133.

[7] ParnaGanguli, SurabhiChaudhuri. Nanomaterials in antimicrobial paints and coatings to prevent biodegradation of man-made surfaces: A review. Materials Today: Proceedings. 2021; 45(3): 3769-3777.

[8] Rotimi S, Oluranti A, Idowu DI, Peter O. Nanotechnology in Paints and Coatings. Advanced Coating Materials. 2018; 175-233.

[9] Vengatesan MR, Mittal V. Surface modification of nanomaterials for application in polymer nanocomposites: an overview Surf Modif Nanoparticle Natural Fiber Fillers. 2015; 1-27.

[10] Tuan AN, Huyen N, Thien VN, Hoang T. Effect of Nanoparticles on the Thermal and Mechanical Properties of Epoxy Coatings. Journal of Nanoscience and Nanotechnology. 2016; 16(9): 9874-9881.

[11] Zahed A. Epoxy in nanotechnology: A short review. Progress in Organic Coatings. 2019; 132: $445-448$. 
[12] Xianming S, Tuan AN, Zhiyong S, Yajun L, Recep A. Effect of nanoparticles on the anticorrosion and mechanical properties of epoxy coating. Surface \& Coatings Technology. 2009; 204: 237-245.

[13] K Burgess, Wang L, Chowdhury RR, Lotus AF, Moula G. Nano-TiO2/polyurethane composites for antibacterial and self-cleaning coatings. Nanotechnology. 2012; 23(42): 425606.

[14] Shyam DM, Purushothaman M, Santhana GKP, and Sanjay K Nayak. Effect of nano-calcium carbonate content on the properties of poly (urethane methacrylate) nanocomposites. Journal of Thermoplastic Composite Materials. 2014; 27(12): 1711-1727.

[15] Wu WS, Queiroz ME, Nelcy DSM. The effect of precipitated calcium carbonate nanoparticles in coatings. Journal of Coatings Technology and Research. 13(2): 277-286.

[16] Massoud M, Yasser H, Mehdi K. Effect of nano-silica on the mechanical properties of acrylic polyurethane coatings. Progress in Organic Coatings. 2016; 101: 477-485.

[17] Priyanka A, Swati G, Ravindra GP. Development and Evaluation of Nano-Silica Dispersed Polyurethane Based Coatings for Improved Anti-Graffiti and Scratch Resistance. Open Journal of Applied Sciences. 2015; 05(12): 808818.

[18] Thien VN, Tuan AN, Hau NT. The Synergistic E_ects of $\mathrm{SiO}_{2}$ Nanoparticles and Organic Photostabilizers for Enhanced Weathering Resistance of Acrylic Polyurethane Coating. Journal of Composites Science. 2020; 4(23): $1-11$.

[19] Yern Chee, Ching, Nurehan Syamimie. Effect of Nanosilica Filled Polyurethane Composite Coating on Polypropylene Substrate. Journal of Nanomaterials. 2013; 4: 1-8.

[20] Massoud M, Yasser H, Alireza FT. Abrasion resistance of acrylic polyurethane coatings reinforced by nano-silica. Progress in Organic Coatings. 2018; 125: 507-515. 